\title{
FATORES DESENCADEADORES DE (IN)SATISFAÇÁO NO TRABALHO DOS ENFERMEIROS DA ATENÇÃO BÁSICA DE SAÚDE
}

\author{
TRIGGERING FACTORS OF JOB (DIS)SATISFACTION AMONG \\ PRIMARY HEALTH CARE NURSES
}

\section{FACTORES DESENCADENANTES DE (IN)SATISFACCIÓN EN EL TRABAJO DE LOS ENFERMEROS DE LA ATENCIÓN BÁSICA DE SALUD}

\author{
Jéssica Mendonça Moreira* \\ Beatriz Francisco Farah** \\ Herica Silva Dutra ${ }^{* * *}$ \\ Nádia Fontoura SANHUdo ${ }^{* * * *}$ \\ Denise Barbosa De Castro Friedrich ${ }^{* * * * *}$
}

\begin{abstract}
RESUMO
A Atenção Básica de Saúde no Brasil é uma das portas de entrada no sistema e organizadora da rede de atenção de saúde. Os enfermeiros são os profissionais mais próximos da população e a incapacidade para atender todas as demandas da mesma gera tensōes e estresse entre usuários e trabalhadores com a assistência ofertada. Objetivo: Descrever os fatores desencadeadores de insatisfação dos enfermeiros no trabalho da Atenção Básica de Saúde. Material e Método: Estudo qualitativo do tipo exploratório descritivo, realizado em 2016, com 19 enfermeiros das unidades de Atençáo Básica de Saúde, em um município da Zona da Mata, estado de Minas Gerais, Brasil. Foram realizadas entrevistas semiestruturadas, até se alcançar a saturação dos dados. Para a análise e interpretaçáo utilizou-se da hermenêutica dialética. Resultados: Emergiu uma categoria: Insatisfação dos enfermeiros com o seu trabalho na Atenção Básica de Saúde e os fatores desencadeadores. Conclusóes: A satisfação dos enfermeiros está relacionada a sua profissão. Alguns encontram-se insatisfeitos com as condiçóes de trabalho. Fatores como sobrecarga de trabalho, escassez de recursos físicos e materiais, infraestrutura inapropriada, desvalorizaçáo profissional, dentre outros, são apontados como causadores de insatisfação, o que pode resultar na cronificação do estresse desencadeando adoecimento.
\end{abstract}

Palavras-chave: Satisfação no trabalho; Atenção Básica de Saúde; Enfermagem.

*Enfermeira, Universidade Federal de Juiz de Fora, Juis de Fora, Minas Gerais. Brasil. Email: jessicamoreira12@gmail.com

**Enfermeira, Universidade Federal de Juiz de Fora, Juiz de Fora, Minas Gerais, Brasil. Email: b-farah@hotmail.com. Autora correspondente.

***Enfermeira. Universidade Federal de Juiz de Fora, Juiz de Fora, Minas Gerais, Brasil. Email: herica.dutra@uff.edu.br

${ }^{* * * *}$ Enfermeira. Universidade Federal de Juiz de Fora, Juiz de Fora, Minas Gerais, Brasil. Email: nadiasanhudo@gmail.com

*****Enfermeira. Universidade Federal de Juiz de Fora, Juiz de Fora, Minas Gerais, Brasil. Email: denisefriedrichenf@gmail.com 


\section{ABSTRACT}

Primary Health Care in Brazil is one of the gateways to the health system and it is the organizer of the healthcare network. Nurses are the closest professionals of the population and the inability to meet all their demands generates tensions and stress between users and workers concerning the delivered care. Objective: To describe the factors triggering the dissatisfaction among nurses working in Primary Health Care. Material and Method: It is a qualitative study of the descriptive exploratory type, carried out in 2016, with 19 Primary Health Care nurses, in a city of the Zona da Mata of Minas Gerais State, Brazil. Semi-structured interviews were conducted until data saturation was achieved. Dialectical hermeneutics was used for the analysis and interpretation. Results: It emerged one category: Nurse's dissatisfaction with their work in Primary Health Care and triggering factors. Conclusions: Nurses' job satisfaction is related to their profession. Some are dissatisfied with working conditions. Factors such as workload, scarce physical and material resources, inappropriate infrastructure, professional devaluation, among others, are indicated as causing dissatisfaction, which can result in chronic stress and cause illness.

Key words: Job satisfaction; Primary Health Care; Nursing.

\section{RESUMEN}

La Atención Primaria de Salud en Brasil es una de las puertas de entrada en el sistema y organizadora de la red de atención de salud. Los enfermeros son los profesionales más cercanos a la población y la incapacidad de atender a todas sus demandas genera tensiones y estrés, entre usuarios y trabajadores, por la asistencia ofrecida. Objetivo: Describir los factores desencadenantes de insatisfacción en el trabajo de los enfermeros de la Atención Primaria de Salud. Material y Método: Estudio cualitativo de tipo exploratorio descriptivo, realizado en 2016, con 19 enfermeros de las unidades de Atención Primaria de Salud, en una municipalidad de la Zona de la Mata, estado de Minas Gerais, Brasil. Se realizaron entrevistas semiestructuradas hasta alcanzar la saturación de los datos. Para el análisis e interpretación se utilizó la hermenéutica dialéctica. Resultados: Emergió una categoría: Insatisfacción de los enfermeros con su trabajo en la Atención Primaria de Salud y factores desencadenantes. Conclusión: La satisfacción de los enfermeros está relacionada con su profesión. Algunos se sienten insatisfechos con las condiciones de trabajo. Los factores como sobrecarga de trabajo, escasez de recursos físicos y materiales, infraestructura inapropiada, desvalorización profesional, entre otros, son señalados como causantes de insatisfacción, que puede resultar en la cronificación del estrés y desencadenar la enfermedad.

Palabras clave: Satisfacción en el trabajo; Atención Primaria de Salud; Enfermería.

Fecha recepção: 08/08/2018

Fecha aceitação: 01/02/2019

\section{INTRODUÇÁO}

No Brasil a Atenção Básica à Saúde (ABS) se traduz no nível primário de atendimento à população usuária do Sistema Único de Saúde (SUS). A ABS é estruturante e uma das portas do sistema, sendo a coordenadora da rede de cuidados de saúde ${ }^{(1)}$. É o nível de atenção mais próximo da população e responsável por identificar e atender as necessidades de saúde da mesma. Preconiza a atenção ao indivíduo, família e comunidade por meio de açóes de promoção da saúde, prevenção e tratamento de doenças e redução de danos e sofrimentos, sob a perspectiva do cuidado integral, considerando a singularidade e a complexidade do indivíduo e sua inserção sociocultural ${ }^{(1,2)}$.

A Estratégia de Saúde da Família (ESF) implantada desde 1996, pelo Ministério da Saúde, foi a principal forma de viabilizar a ABS e o SUS. A ESF preconiza modificar a forma do cuidar, a organização do trabalho e a compreensão do processo saúde-doença. Propóe a centralidade do cuidado nas coletividades considerando o contexto familiar e social. Considera aspectos 
epidemiológicos e sanitários para monitoramento, análise e planejamento das ações de saúde a fim de atender as necessidades de saúde da população. Além disso, amplia e favorece o acesso aos serviços de saúde, neste e nos demais níveis de atenção ${ }^{(3)}$.

$\mathrm{Na}$ ESF, a equipe de saúde é composta de um médico, um enfermeiro, um técnico ou auxiliar de enfermagem e seis Agentes Comunitários de Saúde (ACS). Esse modelo incorpora os princípios do SUS, e a organização e o processo de trabalho seguem as diretrizes e princípios que coadunam com a Política Nacional de Atenção Básica (PNAB) ${ }^{(1)}$.

O município do estudo, a partir de 2014, implantou o Plano Diretor da Atenção Primária à Saúde (PDAPS) que é a principal diretriz para a reestruturação da $\mathrm{ABS}$ no âmbito municipal, que prevê a melhoria dos processos assistenciais, objetivando normatizar a $\mathrm{ABS}$ à luz da gestão do cuidado e qualificar os profissionais de todas as Unidades Básicas de Saúde (UBS).

Os trabalhadores desse nível de atenção estão na linha de frente do sistema e mais próximos da populaçáo, o que estimula o contato e vínculo com a mesma, aumentando o esforço emocional e físico para a resolução dos problemas de saúde ${ }^{(4)}$. Além disso, estão mais expostos a desafios decorrentes da desigualdade social, da proximidade do usuário e das lacunas que o próprio sistema de saúde tem apresentado $^{(2)}$. Essa situação demonstra a fragilidade dos serviços e da incapacidade para atender todas as demandas da população, gerando insatisfação em usuários e trabalhadores com a assistência ofertada ${ }^{(2)}$, e o município do estudo não é exceção.

Além disso, os trabalhadores enfrentam problemas relacionados à infraestrutura inadequada, insuficiência de material e equipamentos para o desenvolvimento das atividades, falta de capacitação dos profissionais ${ }^{(5)}$, falta de continuidade da assistência nos demais níveis de atenção, demonstrando a dificuldade de implantar a rede de atenção à saúde nos municípios, dentre outros fatores ${ }^{(6)}$.

Em relação aos enfermeiros, na $\mathrm{ABS}$ há evidências que apontam a existência de obstáculos no desenvolvimento de suas atividades como sobrecarga de trabalho, baixa remuneração salarial, carência de recursos técnicos e materiais, problemas de relacionamento interpessoal dentro da equipe, condiçóes precárias de trabalho, ambientes de trabalho que podem gerar risco à sua saúde, falta de reconhecimento pelo público assistido, hegemonia médica, entre outros. Esses fatores comprometem a qualidade da assistência prestada aos usuários e geram desmotivação por parte dos profissionais ${ }^{(2,7)}$. A complexidade das necessidades dos usuários e as relaçóes conflitantes no ambiente de trabalho são fatores geradores de estresse vivenciados cotidianamente, levando à insatisfação com o trabalho e à suscetibilidade a adoecimentos ${ }^{(3,8)}$.

A preocupação com a satisfação dos enfermeiros no trabalho tornou-se um assunto de ordem global $^{(9)}$, sendo cada vez mais necessária sua avaliação entre profissionais e organizaçóes, a fim de impactar a qualidade da assistência e eficiência da organização. Esse investimento pode repercutir em melhoria contínua da satisfação de funcionários e retenção de profissionais qualificados e experientes ${ }^{(10)}$.

Algumas estratégias que podem ser adotadas incluem incentivar a afetividade positiva no ambiente de trabalho, pois a mesma foi correlacionada positivamente com a resiliência psicológica e com a satisfação no trabalho. Algumas açóes sugeridas foram o fortalecimento do trabalho em equipe, oportunidade de desenvolvimento e aprendizagem permanente, incentivo ao respeito e confiança para melhorar a satisfação profissional e, ao mesmo tempo, promover a retenção dos profissionais de enfermagem ${ }^{(11)}$.

A satisfação no trabalho é determinada por sentimentos, de ordem emocional e subjetiva, dinâmica, ativa e complexa, variando conforme elementos percebidos pelos indivíduos e suas necessidades, as quais variam entre diferentes pessoas $^{(12)}$. Portanto, as experiências positivas ou negativas vivenciadas no trabalho podem impactar o desempenho do indivíduo e a qualidade da assistência por ele prestada ${ }^{(13,14)}$.

No extremo oposto encontra-se a insatisfação, considerada o contrário da satisfação. Muitas vezes ela relaciona-se a aspectos organizacionais, dificuldades no ambiente de trabalho ${ }^{(15,16)}$, relacionamento interpessoal conflituoso com os componentes da equipe multidisciplinar, sentimentos negativos relacionados ao trabalho ${ }^{(12)}$, dimensionamento de pessoal inadequado, carga de trabalho excessiva e alta rotatividade dos profissionais ${ }^{(11)}$.

Satisfação no trabalho é entendida neste estudo como um fenômeno complexo cuja definição varia conforme o referencial teórico adotado. Configura um conjunto de sentimentos 
favoráveis que os indivíduos apresentam em relação ao trabalho. Portanto, implica em processos subjetivos avaliativos realizados pelo trabalhador, conforme os contextos e as circunstâncias do trabalho. Essa avaliação dinâmica pode determinar insatisfação, dependendo das condiçóes gerais de trabalho oferecidas e a percepção de cada pessoa, influenciando no bem-estar do trabalhador ${ }^{(17)}$.

Em pesquisa realizada no município do estudo observou-se que a variável satisfaçáo no trabalho apresentou associação com a Síndrome de Burnout $(\mathrm{p}<0,001)$ sendo que pessoas com baixo nível de satisfação apresentaram maior prevalência da síndrome ${ }^{(18)}$. Assim, a investigação dos fatores desencadeadores da insatisfação podem favorecer uma melhor compreensão deste fenômeno no processo de trabalho dos enfermeiros da ABS.

Justifica-se, portanto, a realização desta investigação por se entender a importância da insatisfação e seus impactos no gerenciamento do cuidado de enfermagem, pois fazem parte do processo de gerenciamento de recursos humanos e podem influenciar no desempenho profissional.

Diante do exposto, o estudo teve como questão norteadora: ¿quais fatores são desencadeadores de insatisfação no trabalho dos enfermeiros da ABS? Entendendo que o fenômeno do estudo é um contínuo que pode passar entre sujeitos satisfeitos e insatisfeitos, a principal variável foi denominada (in)satisfação. Assim, delimitou-se como objetivo descrever os fatores desencadeadores de (in) satisfação dos enfermeiros no trabalho da Atenção Básica de Saúde.

\section{MATERIAL E MÉTODOS}

Tipo de estudo: Pesquisa descritiva, com abordagem qualitativa. O estudo foi desenvolvido na ABS de um município da Zona da Mata mineira, do estado de Minas Gerais, Brasil, nas Unidades Básicas de Saúde (UBS). As UBS estão subordinadas a Subsecretaria de ABS da Secretaria Municipal de Saúde (SMS). O município possui $61 \mathrm{UBS}$, sendo que 39 UBS adotam o modelo assistencial da Estratégia de Saúde da Família (ESF).

Participantes: A seleção dos participantes incluiu 19 enfermeiras das UBS, que aceitaram participar da pesquisa voluntariamente e assinaram o termo de consentimento livre esclarecido. Os critérios de inclusão foram: ser enfermeiro em efetivo exercício na UBS por no mínimo seis meses. Foram excluídos os enfermeiros de férias e licenças no período da coleta de dados e os que não se disponibilizaram a realizar a mesma. Os nomes das participantes foram substituídos pela letra "E" e por números arábicos de 1 a 19, conforme a sequência das entrevistas. Obteve-se a participação final de 19 enfermeiras. O primeiro contato foi realizado por telefone onde foram explicados os objetivos da pesquisa e a estratégia de coleta de dados. A seguir foi agendado encontro individual no local de trabalho de cada enfermeira.

Coleta de dados: Teve início no dia 08 de setembro de 2016 e término em 05 de outubro de 2016. Os dados foram coletados por meio de entrevistas semiestruturadas, com a seguinte questão norteadora: ¿Quais são os motivos que você considera como desencadeadores de insatisfação no trabalho? As entrevistas foram gravadas em áudio e posteriormente transcritas, havendo apenas a correção de erros de português, evitando a modificação das características básicas do texto e seu referido significado.

Análise dos dados: Foi utilizada a hermenêutica dialética, por reconhecer que, através da hermenêutica, busca-se a compreensão de sentido que se dá na comunicação entre seres humanos, tendo a linguagem como núcleo central e, por meio da dialética, que é a ciência e a arte do diálogo, da pergunta e da controvérsia, busca-se nos fatos, na linguagem, nos símbolos e na cultura, os núcleos obscuros e contraditórios para realizar uma crítica sobre eles ${ }^{(19)}$. A análise dos dados se deu por meio da seguinte trajetória: leitura exaustiva das entrevistas, ordenação dos dados, classificação dos dados, identificação dos núcleos de significância, emersão das categorias empíricas e análise final ${ }^{(19)}$. Para a operacionalização da análise de dados, foi utilizado um quadro de análise ${ }^{(20)}$.

Após a identificação dos núcleos de sentido, as unidades representadas pelos fragmentos das falas dos entrevistados foram relacionadas a cada núcleo de sentido. Foram organizadas as sínteses horizontal (que corresponde às unidades formadoras do núcleo de sentido) e vertical (possibilita uma ideia geral de cada entrevistado sobre os núcleos de sentido), que após a leitura transversal e o confronto das ideias ${ }^{(20)}$ possibilitou emergir a categoria de análise. Obtevese as falas das 19 enfermeiras em ambos os núcleos 
de sentido. Foram realizadas as sínteses horizontal e vertical das falas relativas das 19 participantes em cada um dos núcleos de sentido, conforme Quadro 1. A pesquisa teve início, após a aprovação no comitê de ética em pesquisa com seres humanos da Universidade Federal de Juiz de Fora (UFJF), CAAE: 57825716.0.0000.5147, parecer No 1.661.471.

\section{RESULTADOS}

Características dos participantes: Das 19 enfermeiras participantes, a maioria era casada $(76,6 \%)$; a faixa etária variou entre 31 a 40 anos $(42,1 \%)$; de 41 a 50 anos $(10,6 \%)$ e de 51 a 60 anos (47,3\%). A maioria das entrevistadas apresentava tempo de formação superior a 10 anos; e possuía pós-graduação $(99,8 \%)$. O tempo de conclusão da graduação variou entre 7 a 32 anos, tendo a maioria dos participantes $(31,6 \%)$ entre 7 e 9 anos. $\mathrm{O}$ tempo de atuação na $\mathrm{ABS}$ variou entre 8 meses a 25 anos, sendo que a maioria $(57,8 \%)$ trabalhavam na ABS entre 8 meses a 4 anos.

Fatores desencadeadores de (in)satisfação dos enfermeiros no trabalho da Atenção Básica de Saúde: Emergiu uma categoria de análise: Insatisfação dos enfermeiros na ABS (Quadro 1), composta por dois núcleos de sentido: (In) satisfação no trabalho e fatores desencadeadores de insatisfação.

(In)satisfação no trabalho. O núcleo de sentido que emergiu das falas dos participantes permitiu identificar o nível de insatisfação referido pelas enfermeiras, classificados em satisfeito, parcialmente satisfeito e insatisfeito.

Em relação à satisfação:

Eu estou muito satisfeita no meu trabalho. Hoje eu me considero assim uma enfermeira produtiva, eu consigo produzir (...) devido à experiência obtida nesses anos, hoje eu tenho mais tranquilidade em desenvolver (o trabalho). Eacho que desenvolvo mais confiante e isso me deu certa realização, de fazer bem feito, de tentar fazer bem feito. Continuo procurando, estudando né, não paro ai. Eu acho que isso faz no meu dia a dia, enquanto profissional, me sentir realizada. Eu me sinto realizada no que eu faço né (E8).

Quanto à insatisfação:

Eu não me sinto satisfeita, não com meu trabalho em si, porque eu tenho claramente na minha cabeça que eu faço o melhor que posso, mas a insatisfação de você não ter o apoio necessário para você fazer é muito ruim (...) então assim, a gente fica muito sobrecarregada, o número de pessoas que a gente atende é muito grande, o controle que a gente tem que ter é muito difícil (...) a sensação que eu tenho é que meu trabalho não está saindo do papel. O esforço que eu estou fazendo não é suficiente (E6).

Alguns referiram estar parcialmente satisfeitos:

É assim, eu não posso dizer nem que sim 100\% e nem que não $100 \%$, é meio termo. O sim significa que eu adoro a equipe que eu trabalho, é uma equipe muito comprometida, a gente trabalha junto. A população que a gente trabalha é a uma população carente e eu gosto de trabalhar com esse tipo de população. Hoje a satisfação é que a gente é concursada, a gente tem

Quadro 1: Núcleos de sentidos que emergiram das entrevistas, 2016.

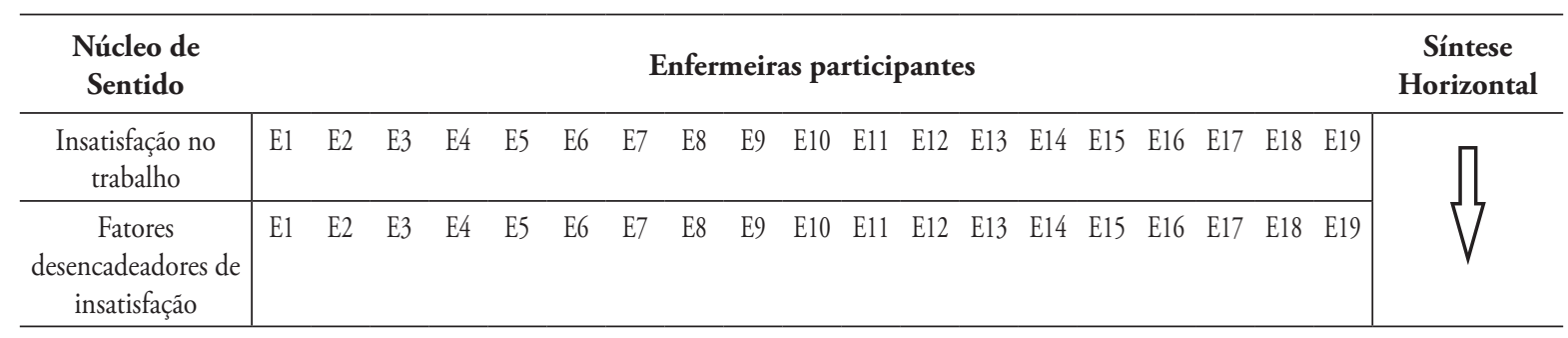

Síntese Vertical

Fonte: Adaptado pela autora de Alencar; Nascimento; Alencar, 2012. 
estabilidade. O que é ruim, o que me faz insatisfeita é a questão de recursos em geral (...) questão salarial, que às vezes a gente vê que não tem a valorização que a gente deveria ter (E13).

Eu encontro em parte satisfeito, porque eu gosto daquilo que eu faço. Muitas vezes a falta de reconhecimento da enfermagem, do trabalho que a gente faz, do exagero das coisas que a gente tem para fazer, da cobrança, às vezes nem há tempo para fazer tudo. E a gente tem que se virar para fazer tudo, e isso é a causa de angústia na gente (E16).

Fatores desencadeadores de insatisfaçáo. Os enfermeiros citaram que os motivos que geravam insatisfação estavam relacionados ao ambiente de trabalho: não conseguir resolver todos os problemas, muitas vezes por causa de tempo escasso e ser referência para solução de todas as situaçóes de conflito da unidade; escassez de recursos humanos, físicos e materiais; sobrecarga de trabalho; grande demanda espontânea da população por atendimentos; falta de apoio e respaldo necessário para o desenvolvimento de suas atividades; cobrança dos usuários para a solução dos problemas; reclamações de gestores, colegas de trabalho e usuários; desvio de função; o complexo trabalho em equipe:

Gosto do que eu faço gosto da minha profissão (...) trabalhar insatisfeito gera outros problemas, né? Eu procuro trabalhar com satisfação. Encontro algumas situaçôes que me deixa insatisfeita. As condiçôes de trabalho precisam ser melhores, isso inclui recursos materiais, insumos, que estamos lidando com falta desses. Também questão/limitação de recursos humanos que gera sobrecarga para os profissionais que estão trabalhando (E5).

Outra dificuldade citada nesse estudo é a falta de compreensão por parte da população e de alguns profissionais com relação ao PDAPS proposto pelo município:

As vezes os usuários eles não entendem a nova forma de trabalhar com agendamento, eles não querem saber, eles querem ser atendidos em consulta. Então todo dia você tem esse tipo de problema. Isso vai minando energia (...). E com esse plano diretor na nossa cabeça, que acabou explodindo na mão do enfermeiro (E9).

Pode-se verificar nas unidades representativas das falas de alguns enfermeiros que os fatores geradores de estresse em seu processo de trabalho podiam ocasionar adoecimentos:

No geral eu acho que todo trabalhador da saúde da atenção básica tem muita insatisfação sim, mesmo pela desvalorização do trabalho, pela carga de trabalho e de coisas que a gente tem que fazer, e muitas vezes a gente deixa de fazer realmente aquilo que é proposto (...) e isso desgasta muito a gente. Tem coisas boas, mas as coisas que desencadeiam as doenças na gente são muito maiores (E16).

O complexo relacionamento do enfermeiro com a equipe da unidade em sua rotina de trabalho e a difícil relação profissional-usuário, foram identificados como fatores geradores de insatisfação em seu trabalho:

Tem paciente que briga com você e você não pode retrucar isso, náo pode falar. Então isso deixa muito estressado (E13).

Eu fico realmente mais tempo aqui e se um ambiente é doente, onde você não gosta do colega, onde você tem uma recha, você adoece por conta disso (...) a gente tem muitos profissionais doentes (E3).

A falta de equipe, do trabalho em equipe, essa concorrência (...) é o que tem me adoecido também (E11).

Os entrevistados também estavam expostos a fatores organizacionais do sistema de saúde e durante o período da pesquisa o modelo assistencial de saúde passava por transformaçóes geradas pelo PDAPS, causando tensóes e pressóes aos membros das equipes por mudanças:

OSUS éperfeito no papel, mas a má administração, a organização está errada de como funciona a estrutura. Hoje tudo está informatizado, mas ainda estamos preenchendo papel, e a gente tem que cumprir meta em cima de um papel, que você ainda manda para digitar (...) a gente não tem suporte satisfatório, então acho que isso angustia muito. Mas, a gente tem que saber que a gente tem o limite nosso e trabalhar com isso, porque senão vira um sofrimento e vira adoecimento mesmo. As férias têm que ser regulares, porque senão você chega ao seu limite (E19).

\section{DISCUSSÃO}

O perfil das participantes vai ao encontro de um estudo de amplitude nacional que identificou maioria do sexo feminino com até $40 \operatorname{anos}^{(21)}$. 
Destaca-se nesta pesquisa que as equipes passavam pela implantação da estratégia do PDAPS, trazendo mudanças no âmbito organizacional, no processo de trabalho e educacional dos profissionais ${ }^{(22)}$.

Os entrevistados explicaram que sua satisfaçáo no trabalho advém do fato de gostar da profissão, da certeza que desenvolvem seu trabalho corretamente, do prazer em exercer suas funçôes, indo ao encontro de outra investigação ${ }^{(2)}$. Foi mencionada a realização profissional, gratificação pessoal por suas atividades, orgulho pelo que faz, satisfação e identificação com suas tarefas, como sendo vivências que causam prazer nos profissionais. Apontaram que a realização profissional tem a ver com a identificação do enfermeiro com as atividades desenvolvidas, ou seja, a apreciação positiva do trabalho realizado, em consonância com as políticas públicas da instituição. Essa realização profissional beneficia a inclusão e sensibilização dos trabalhadores para o desenvolvimento laboral, o que resulta em um estado de prazer $^{(2)}$. Outro estudo correlacionou a satisfação no trabalho com as características pessoais e laborais dos participantes, demonstrando que não houve correlação entre satisfação e idade, grau de instrução e tempo de serviço ${ }^{(23)}$.

Nessa pesquisa verificou-se que apesar das falhas do sistema de saúde, de insuficiências nas condiçóes laborais, e deficiências na organização no contexto dos serviços, existem profissionais que encontravam a satisfação em seu ambiente de trabalho. $\mathrm{O}$ fato de os enfermeiros gostarem das atividades que executam e da profissão, afeta positivamente o desempenho profissional e a organização do trabalho, mesmo com todas as dificuldades encontradas no cotidiano do mesmo. Outro fator é a boa relação com o usuário, família e comunidade, a qual muitas vezes imprime significado ao labor.

A insatisfação no trabalho aparece associada ao ambiente e às situações conflitantes em decorrência da falta de material, sobrecarga, desvalorização do enfermeiro e conflitos na equipe. Relatam que tais situaçóes diminuem a qualidade do serviço prestado por eles e colocam em risco a identidade profissional desta classe, dificultando o trabalho em equipe. Além disso, compromete a qualidade de vida no trabalho e pessoal desses profissionais por não estarem satisfeitos coma forma que realizam as atividades.

A satisfação global no trabalho é um dos principais componentes da satisfação geral com a vida ${ }^{(24)}$. Assim, percebe-se que os enfermeiros conseguem identificar e avaliar as consequências de trabalharem insatisfeitos, e do comprometimento com trabalho e com o seu bem-estar geral, o que torna sua rotina diária árdua podendo gerar estresse e adoecimentos.

Por sua própria natureza, o trabalho da enfermagem é especial, porque é mais susceptível a estressores ocupacionais e situaçóes geradoras de insatisfação em seu labor ${ }^{(25)}$. Os enfermeiros convivem no ambiente de trabalho com componentes ameaçadores desse meio a todo instante, como por exemplo: o número reduzido de profissionais para realizar o devido atendimento em saúde; a falta de reconhecimento desses trabalhadores; a falta de recursos, estrutura física inadequada; o excesso de atividades que executa; além da questão da baixa remuneração salarial ${ }^{(26)}$.

A maioria da população não entende a dinâmica do nível primário de atenção à saúde. Mas também alguns profissionais náo se encontram preparados para atender as necessidades da população de maneira adequada, faltando capacitação para uma abordagem integral.

As mudanças geralmente são situaçôes que provocam insegurança, rejeição ao novo, medo de mudar o que já faziam, dentre outros sentimentos. A situação das unidades, como já descrita, passava por insuficiência de várias naturezas, que frente à implantação do novo modelo organizacional, gerou uma demanda maior por serviços, em virtude do próprio arranjo que o PDAPS propunha.

Os enfermeiros, historicamente abraçam as propostas políticas na saúde ${ }^{(27)}$, não sendo diferente com os enfermeiros da ABS deste estudo, ao assumirem a proposta do PDAPS. Portanto, uma das açóes importantes de imprimirem em suas práticas, é a reflexão do seu processo de trabalho e das condiçôes de trabalho a que estão submetidos. Acredita-se que estas são ações para iniciarem um processo de valorização e reconhecimento da categoria, que pode ser desenvolvida por meio da educação permanente como um dispositivo de potencial espaço para o diálogo e de permanente reflexão.

A persistente imagem de submissão do enfermeiro aos demais membros da equipe $\mathrm{e}$ equivocada imagem de serviço caritativo, são marcas da trajetória histórica da profissão, que ainda permanecem vivas na mente das pessoas. Tanto a população quanto os demais profissionais de saúde 
parecem desconhecer a importância da enfermagem para o cuidado em saúde, não a valorizando. Observa-se ainda na atualidade uma imagem da enfermagem ser prestadora de serviço aos demais membros da equipe de saúde, principalmente o médico e não à população. Subentende-se que a interpretação, muitas vezes errônea, relacionada à figura do enfermeiro decorre da inexistência de conhecimento da populaçáo da indiscutível importância desse profissional na saúde ${ }^{(28)}$.

Acredita-se que a desvalorização da Enfermagem contribua para sua posição de reduzida visibilidade, resultando em sofrimento e insatisfação aos trabalhadores, tornando mais difícil suas relaçóes com a equipe multiprofissional e o exercício da autonomia do mesmo, podendo intensificar a pouca visibilidade da profissão e remuneração salarial não condizente com as atividades exercidas, consequentemente ocasionando dificuldade no exercício de suas ações no cotidiano ${ }^{(28)}$.

O reconhecimento por parte da chefia foi relacionado diretamente à produtividade, cumprimento das metas e exigência da organização do trabalho ${ }^{(2)}$. Essa situação também é vivenciada no cotidiano dos enfermeiros desse estudo, caracterizado como relaçóes complexas que imprimem ao enfermeiro situaçóes de estresse, angústia e sofrimento. Todavia, o reconhecimento por parte dos usuários pode ser considerado determinante contra o esgotamento profissional ${ }^{(2)}$.

A deficiência dos recursos humanos e materiais e as precárias condiçóes de trabalho oferecidas aos enfermeiros e demais trabalhadores, têm sido consideradas situaçóes penalizadoras que prejudicam diretamente a qualidade do serviço prestado à população, gerando insatisfação nos profissionais que se sentem impotentes e frustrados com a situação ${ }^{(29)}$.

A sobrecarga de trabalho foi o fator mais apontado pelos enfermeiros. $\mathrm{O}$ enfermeiro diariamente trabalha com uma equipe, a qual gerencia. Ela é constituída muitas vezes por profissionais em número insuficiente e que nem sempre estão devidamente qualificados, expondoos assim a situações estressantes ${ }^{(30)}$. Além disso, podem ser responsabilizados pela assistência de enfermagem precária e receber críticas dos superiores, dos usuários e de outros profissionais de saúde ${ }^{(31)}$.

Apesar de todos os problemas enfrentados os enfermeiros da ABS dessa pesquisa não param o seu trabalho e tentam desenvolvê-lo da melhor maneira e condiçóes possíveis. Talvez, em virtude da demanda da população, que é grande, e os consomem no seu cotidiano, falte tempo para que reflitam seu processo de trabalho e se autoavaliem sobre suas condições de saúde.

A enfermagem é uma profissão cuja formação foi e ainda é muito voltada para o modelo biológico-tecnicista, podendo deixar a sensação no profissional de desvalorização das açóes desenvolvidas e sobrecarga de trabalho por não conseguir gerenciar toda demanda e conflitos existentes nas UBS, advindo da insuficiência de conhecimentos para organizar, planejar e realizar açóes que auxiliam no desenvolvimento do seu trabalho em nível primário ${ }^{(2)}$.

Em virtude de toda essa complexidade no trabalho do enfermeiro na ABS, a enfermagem vem sendo estudada e apontada como uma das profissóes mais suscetíveis ao burnout ${ }^{(32)}$. Portanto vale ressaltar, que a insatisfação de alguns profissionais dessa pesquisa e as condições laborais a que estão inseridos podem levar ao adoecimento dos mesmos. Desse modo, o bem-estar e a saúde ocupacional geram impactos sobre a organização e também implicações para a sociedade em geral $^{(32)}$.

\section{CONCLUSÓES}

A (in)satisfação está no enfrentamento conjunto dos trabalhadores, gerência das UBS e gestão da ABS, de reconhecer, acompanhar e avaliar os fatores causadores de insatisfação.

Investir em infraestrutura, tecnologias adequadas e na valorização do profissional e educação permanente em saúde, são fatores primordiais para que a assistência de enfermagem seja realizada com qualidade e que o direito de dignas condiçóes de trabalho seja garantido.

Acredita-se que gestores, profissionais e usuários do sistema poderão se valer destas informaçóes para melhorias na organização e planejamento da ABS.

Como limite do estudo destaca-se que os dados foram obtidos em um momento que o município passava por uma mudança e transformação no processo de trabalho. Entende-se que todo processo de mudança acarreta alteração do status quo e incômodos, portanto os achados refletem o 
momento específico que os profissionais estavam vivenciando.

\section{REFERÊNCIAS}

1. Portaria no $2436 / \mathrm{GM} / \mathrm{MS}$, de 21 de setembro de 2017 [Internet]. Brasil: Ministério da Saúde; 2017 [citado 2018 fev 21]. Disponível em: http:// bvsms.saude.gov.br/bvs/saudelegis/gm/2017/ MatrizesConsolidacao/comum/250584.html

2. Maissiat GS, Lautert L, Pai DD, Tavares JP. Contexto de trabalho, prazer e sofrimento na atenção básica em saúde. Rev Gaúcha Enferm. 2015; 36(2): 42-9.

3. Lima L, Pires DEP, Forte ECN, Medeiros F. Satisfação e insatisfação no trabalho de profissionais de saúde da atenção básica. Esc Anna Nery. 2014; 18(1): 17-24.

4. Lopes AS, Vilar RLA, Melo RHV, França RC S. O acolhimento na Atenção Básica em saúde: relaçôes de reciprocidade entre trabalhadores e usuários. Saúde debate. 2015; 39: 114-23.

5. Farah BF, Dutra HS, Ramos ACTM, Friedrich DBC. Percepções de enfermeiras sobre supervisão em enfermagem na Atenção Primária à Saúde. Rev Rene. 2017; 17(6): 804-11.

6. Fertonani HP, Pires DEP, Biff D, Scherer MDA. Modelo assistencial em saúde: conceitos e desafios para a atenção básica brasileira. Ciênc saúde coletiva. 2015; 20: 1869-78.

7. Merces MC, Silva DS, Lopes RA, Lua I, Silva JK, Oliveira DS et al. Síndrome de Burnout em enfermeiros da atenção básica à saúde. Rev Epidemiol Control Infect. 2015; 5(2): 100-4.

8. Khamisa N, Peltzer K, Ilic D, Oldenburg B. Work related stress, burnout, job satisfaction and general health of nurses: A follow-up study. Int J Nurs Pract. 2016; 22(6): 538-45.

9. Benton DC, Ferguson SL. A wide-angle view of global nursing workforce and migration. Nurs Econ. 2017; 35(4): 170-8.

10. Stam LMP, Laschinger HKS, Regan S, Wong CA. The influence of personal and workplace resources on new graduate nurses' job satisfaction. J Nurs Manag. 2015; 23(2): 190-9.

11. Yang J, Tang S, Zhou W. Resiliencia psicológica y satisfacción laboral de enfermeros: el efecto mediador de la afectividad positiva. Revista Argentina de clínica psicológica. 2017; 26(2): 194201.

12. Sartoreto IS, Kurcgant P. Satisfação e Insatisfação no trabalho do Enfermeiro. R bras ci Saúde. 2017; 21(2): 181-8.
13. Morais BX, Pedro CMP, Dalmolin GL, Silva AM. Satisfação profissional de trabalhadores de enfermagem de um serviço de hemato-oncologia. Rev Rene. [Internet]. 2018 (citado 2018 out 2); 19: e3165. Disponível em: http://periodicos.ufc. $\mathrm{br} /$ rene/article/view/31317/pdf

14. Platis C, Reklitis P, Zimeras S. Relation between job satisfaction and job performance in healthcare services. Procedia-Social and Behavioral Sciences. 2015; 175: 480-7.

15. Nantsupawat A, Kunaviktikul W, Nantsupawat $\mathrm{R}$, Wichaikhum OA, Thienthong $\mathrm{H}$, Poghosyan L. Effects of nurse work environment on job dissatisfaction, burnout, intention to leave. Int Nurs Ver. 2017; 64(1): 91-8.

16. Al-Hamdan Z, Manojlovich M, Tanima B. Jordanian nursing work environments, intent to stay, and job satisfaction. J Nurs Scholarsh. 2017; 49(1): 103-10.

17. Castaneda GA, Scanlan JM. Job satisfaction in nursing: a concept analysis. Nurs Forum (Auckl). 2014; 49(2): 130-8.

18. Lima AS, Farah BF, Bustamante-Teixeira MT. Análise da prevalência da Síndrome de Burnout em profissionais da atenção primária em saúde. Trab educ saúde. 2018; 16(1): 283-303.

19. Minayo MCS. O desafio do conhecimento: pesquisa qualitativa em saúde. São Paulo: Hucitec; 2006. 406 p.

20. Alencar TOS, Nascimento MAA, Alencar BR. Hermenêutica dialética: uma experiência enquanto método de análise na pesquisa sobre o acesso do usuário à assistência farmacêutica. Rev Bras Promoç Saúde. 2012; 25(2): 243-50.

21. Machado MH, Filho WA, Lacerda WF, Oliveira E, Lemos W, Wermelinger $\mathrm{M}$ et al. Características gerais da enfermagem: o perfil sociodemográfico. Enferm Foco Brasília. 2016; 7(Esp): 9-14.

22. A Estratégia de Implementação do Plano Diretor de Atenção Primária à Saúde PDAPS-Juiz de Fora. [Internet]. Brasil: Secretaria de Saúde; 2014 [citado 2017 set 23]. Disponível em: https://www. pjf.mg.gov.br/secretarias/ss/plano_diretor/docs/ implantacao.pdf

23. Magaña MGP, Soto MEJ. Nivel de satisfacción percibida por enfermería con el servicio otorgado por la central de equipos y esterilización. Revista Conamed. 2016; 21(3 Supl); 133-9.

24. Locke EA. The nature and causes of job satisfaction In: Dunette MD (Ed.). Handbook of industrial and organisational psychology. Chicago: RandMcNally; 1976.

25. Puerto JC, Soler LM, Montesinos MJL, Marcos AP, Chorda VMG. Uma nova contribuição para a classificaçấo dos fatores estressores que afetam 
os profissionais de enfermagem. Rev Lat Am Enfermagem. [Internet] 2017 (citado 2018 jun 23); 25: e2895. Disponível em: http://www.scielo. br/pdf/rlae/v25/pt_0104-1169-rlae-25-e2895.pdf

26. Sá AMS, Martins-Silva PO, Funchal B. Burnout: o impacto da satisfação no trabalho em profissionais de enfermagem. Rev Psicol Soc. 2014; 26(3): 66474.

27. Rizzotto MLF. Editorial. Revista Divulgação para Saúde em Debate 2016; 56: 4-7.

28. Avila LI, Silveira RS, Lunardi VL, Fernandes GFM, Mancia JR, Silveira JT. Implicaçóes da visibilidade da enfermagem no exercício profissional. Rev Gaucha Enferm. 2013; 34(3): 102-9.

29. Lorenz VR, Guirardello EB. The environment of professional practice and Burnout in nurses in primary healthcare. Rev Lat Am Enfermagem. 2014; 22(6): 926-33

30. Farah BF, Dutra HS, Sanhudo NF, Costa LM. Percepçáo de enfermeiros supervisores sobre liderança na atenção primária. Rev Cuid. 2017; 8(2): 1638-55.

31. Viegas APB, Carmo RF, Luz ZMP. Fatores que influenciam o acesso aos serviços de saúde na visão de profissionais e usuários de uma unidade básica de referência. Saúde e Soc. 2015; 24(1): 100-12.

32. Adriaenssens J, De Gucht V, Maes S. Determinants and prevalence of burnout in emergency nurses: a systematic review of 25 years of research. Int J Nurs Stud. 2015; 52(2): 649-61. 